\title{
Depressed skull fracture: Prognosis of patients after conservative or surgical management
}

\author{
Haresh Vala ${ }^{1}$, Maulik A Vaja ${ }^{2 *}$ \\ ${ }^{1}$ Associate Professor, ${ }^{2}$ Neurosurgeon, Dept. of Surgery, ${ }^{1}$ Shantaba Medical College and General Hospital, Amreli, Gujarat, ${ }^{2}$ Sterling \\ Hospital, Vadodara, Gujarat, India
}

*Corresponding Author: Maulik A Vaja

Email: rockki1234@gmail.com

\begin{abstract}
Introduction: The fracture of skull is considered as severe injury and have grave prognosis. It is mainly because of complications of the acute head injury affect the brain directly or indirectly. Compound depressed fractures are surgical emergencies and unless treated promptly and properly complications like meningitis, cerebral abscess and osteomyelitis of skull may occur.

Objectives: to determine the causes of depressed fracture skull and its complications and also to find out various presentation and severity of depressed skull fracture and effective modality of management.

Materials and Methods: A prospective study undertaken at department of surgery in coordination with emergency department. Detailed inquiry was done about history of demographic data, presenting symptoms and other diseases done. General, central nervous system examination, other systems examination and local examination were done thoroughly and documented. Patients were treated according conservatively and operatively as per decision taken by surgeon.

Results: Out of total 100 patients, assault (43\%) was most common, followed by vehicular accident (41\%), fall of patients (15\%) and fall of object on the patients (1\%). Patients with severe head injury (GCS<8) were 16 with 7 death after management. Among 94 cases of compound fractures, 34 cases frontal region, 6 had temporal, 9 had fronto-parietal, 25 had parietal, 15 had temporo-parietal and 6 had occipital fracture. Dura tear was seen in $21 \%$ of the cases. Among total 100 patients 44 treated operatively and 56 treated conservatively.

Conclusion: Conservative management is better in patients with CT scan suggestive of depressed skull fracture nor more than 10 mm and not intracranial hematoma. Patients with depressed skull fracture with more than $10 \mathrm{~mm}$ with severe head injury and associate hematoma are better managed operatively.
\end{abstract}

Keywords: Depressed skull fracture, Operative management, Conservative management.

\section{Introduction}

Primary and continuing care of patient who has sustained head injury is responsibility of general and orthopedic surgeons. However surgeons must be able to decide when there is a clear indication for urgent surgery without specialized investigation, mostly because the rate of deterioration does not allow any further delay. ${ }^{1}$

Skull fracture result from large energy forces applied to the head during surgery. The extent and type of skull fracture is determined by kinetic energy of the striking object, the geometry of striking object, the direction of the impact force and anatomical site of the impact. In general person the fracture of skull is considered as severe injury and have grave prognosis. It is mainly because of complications of the acute head injury affect the brain directly or indirectly. And it is uncommon to find the fracture in patient who had serious brain damage without a fracture. ${ }^{2}$ However it is depress skull fracture, which present most striking disparity between brain damage and impairment of consciousness.

It is relatively uncommon for a fractured skull to be recognizable on clinical ground alone. The finding of a depressed fractured skull is a most significant in the patient who is otherwise relatively well and in whom the fracture may provide the only definite evidence that significant violence has been done to the head and may also alert the clinician to the possibility of complication such as intracranial hemorrhage or infection. ${ }^{3,4}$

These are uncommon events, but they are distinctly rare in patients without a depressed skull fracture. Therefore it remains rational to recognize that patient who otherwise appears to have been trivially injured but who have a depressed fracture are more severely affected than those who do not have depressed fracture. It is in patients who have other obvious evidence of brain damage that the presence of a fracture is less significant. Although even in them, the location and type of fracture may influence management.

Compound depressed fractures are surgical emergencies and unless treated promptly and properly complications like meningitis, cerebral abscess and osteomyelitis of skull may occur. Also post treatment epilepsy may supervene. Early definitive diagnosis and management of skull fracture decrease morbidity and mortality as well as achieving maximal functional and aesthetic rehabilitation. ${ }^{5}$ 
So, the aim of the study was to determine the causes of depressed fracture skull and complications following depressed skull fracture. Also, to find out various presentation and severity of depressed skull fracture and effective modality of management.

\section{Materials and Methods}

This was a prospective study undertaken at department of surgery in coordination with emergency department in a tertiary care center of central Gujarat region. Human Ethics Research committee permission was taken before starting the study.

All patients with clinically palpable depressed skull fracture as well as CT scan showed the depress skull fracture were included in the study. Written informed consent was taken from legal guardian of the patient before enrolment in the study. The through inquiry done about a detailed history like age, gender, occupation, mode of injury, time and date of injury, History of unconsciousness, vomiting, convulsion, ear or nose bleeding, abdominal pain, abdominal distension, chest pain, breathlessness or other symptoms.

If patients had received any treatment anywhere following injury, details of the treatment was noted in detail. General examination for vital signs, shock, pallor, cyanosis, black eye and conjunctival hemorrhage was done. Examination of central nervous system function like higher function, Glassgow coma scale (GCS), cranial nerve, pupil, reflexes, motor and sensory system signs of meningeal irritation, back and spine examination were done. Other system examination like per-abdominal, respiratory and cardiovascular system was done in all patients. Local examination including wound, local swelling, pelvic compression test, chest compression test was performed in every case. Routine blood, urine and radiological investigation including CT scan were done in all the patients.

All patients were treated conservatively with intravenous antimicrobial agents, analgesics, anticonvulsants, and mannitol or furosemide. However 3 patients were operated because of early epilepsy and deterioration of GC scale and CT scan was showing more than $10 \mathrm{~mm}$ depression, associated intracranial hematoma, midline shift and signs of hemiplegia. Operative procedure done was simple elevation of closed as well as compound depressed fracture.

Statistical analysis of the descriptive data was done with the help of Microsoft excel sheet.

\section{Results}

Total 100 cases of depressed fracture skull were studied in two and half years. The peak age of the skull fracture was 21 to 30 years with $26 \%$ followed by $23 \%$ in $31-40$ years of age [Table 1]. The gender wise distribution shows Male have $83 \%$ incidence and Female have 17\% only [Fig. 1].

Assault was responsible for $43 \%$ of the cases followed by vehicular accident in $41 \%$ of the cases for the depressed skull fracture. Gender wise distribution shows that assault was responsible in $35 \%$ of male cases and vehicular accident was also common with male with frequency of $33 \%$ among the male. The cause of injury among children $<10$ years of age shows that $2 \%$ male and $3 \%$ female were had injury because of vehicular accident. So, Vehicular accident was the cause in $41 \%$ of the cases among them $5 \%$ were children $<10$ years of age [Table 2].

Commonest presentation was vomiting in 55 patients followed by unconsciousness (20), convulsion (20) and shock (5). [Table 3] Out of total 100 cases compound fracture was seen in $94 \%$ of cases while $6 \%$ were closed. Dura tear was seen in $21 \%$ of the cases. Among these patients with compound fractures 34 cases had fracture in frontal region, 6 had temporal, 9 had fronto-parietal, 25 had parietal, 15 had temporo-parietal and 6 had occipital fracture [Fig. 2].

Out of 57 patients with minor head injury (GCS 13-15), $45(78.95 \%)$ were managed conservatively and $12(21.05 \%)$ operatively. Similarly out of 27 patients with moderate head injury (GCS 8-12), 7 (25.93\%) were managed operatively and out of 16 with severe head injury (GCS <8), 12 (75\%) were managed operatively. So, total 56 patients were treated with conservative management. 7 (43.75\%) patients died after management among the severe head injury [Table 4]. Among all participants $95 \%$ were given analgesics, $85 \%$ were given anticonvulsants, $80 \%$ antibiotics, and $40 \%$ steroids. Also $90 \%$ were given intravenous fluids and $75 \%$ required oxygen.

Table 5 shows the distribution of all patients who are managed operatively. According to that, patients with frontal injury [20(45.45\%)] required higher rate of operative management. Among operative management elevation with durorhaphy was the commonest procedure required in 21 (47.73\%), followed by elevation only [10(22.73\%)], elevation with epidural hemorrhage drainage [10(22.73\%)], and elevation with subdural hemorrhage drainage [3(6.82\%)] [Table 6]. Two patients required endotracheal intubation and 13 patients required tracheostomy.

Complications like intracranial hematoma, both extradural hematoma (16\%) and subdural hematoma (4\%), postoperative infections (3\%), subarachnoid hemorrhage 
(1\%) seen found [Table 7]. Common associated injury was injury to extremities (30\%), blunt chest injury (25\%), pelvis injury (23\%), blunt abdominal injury $(15 \%)$, and spinal injury (7\%) [Table 8]. Table 9 shows numbers of hospital days stayed. Patients with minor head injury stayed 4-5 days and moderate to severe injury stayed 10-30 days.
Table 1: Age wise distribution of all participants

\begin{tabular}{|l|c|}
\hline Age & No of participants (\%) \\
\hline $0-10$ & $6(6 \%)$ \\
\hline $11-20$ & $21(21 \%)$ \\
\hline $21-30$ & $26(26 \%)$ \\
\hline $31-40$ & $23(23 \%)$ \\
\hline $41-50$ & $17(17 \%)$ \\
\hline $51-60$ & $5(5 \%)$ \\
\hline 61 and above & $2(2 \%)$ \\
\hline Total & $100(100 \%)$ \\
\hline
\end{tabular}

Table 2: Causes of depressed skull fracture

\begin{tabular}{|l|c|c|c|c|c|}
\hline Causes & \multicolumn{2}{|c|}{ Age > 10 years } & \multicolumn{2}{c|}{ Age < 10 years } & Numbers (\%) \\
\hline & Male & Female & Male & Female & \\
\hline Assault & 35 & 8 & 0 & 0 & $43(43 \%)$ \\
\hline Fall of patient & 14 & 1 & 0 & 0 & $15(15 \%)$ \\
\hline Fall of object on the patient & 0 & 0 & 1 & 0 & $1(1 \%)$ \\
\hline Vehicular accident & 31 & 5 & 2 & 3 & $41(41 \%)$ \\
\hline Total & 80 & 14 & 3 & 3 & $100(100 \%)$ \\
\hline
\end{tabular}

Table 3: Distribution of all patients according to mode of presentation

\begin{tabular}{|l|c|}
\hline Mode of presentation & Number of patients (\%) \\
\hline Unconscious & $20(20 \%)$ \\
\hline Vomiting & $55(55 \%)$ \\
\hline Convulsion & $20(20 \%)$ \\
\hline Shock & $5(5 \%)$ \\
\hline
\end{tabular}

Table 4: Distribution of patients according to the severity of head injury, management and morbidity

\begin{tabular}{|l|c|c|c|c|c|c|}
\hline Severity of Head injury & No & \multicolumn{2}{|c|}{ Management } & \multicolumn{2}{|c|}{} \\
\hline & & Operative & Conservative & Mortality & Morbidity & Good recovery \\
\hline $\begin{array}{l}\text { Minor } \\
\text { GCS (13-15) }\end{array}$ & 57 & 12 & 45 & 0 & 4 & 53 \\
\hline $\begin{array}{l}\text { Moderate } \\
\text { GCS (8-12) }\end{array}$ & 27 & 20 & 07 & 0 & 6 & 21 \\
\hline $\begin{array}{l}\text { Severe } \\
\text { GCS (<8) }\end{array}$ & 16 & 12 & 4 & 7 & 3 & 6 \\
\hline Total & 100 & 44 & 56 & 7 & 13 & 80 \\
\hline
\end{tabular}

Table 5: Region wise distribution of patients that are managed operatively

\begin{tabular}{|l|c|c|c|c|c|c|c|}
\hline \multicolumn{1}{|c|}{ Head injury } & Frontal & Temporal & Fronto-parietal & Parietal & Temporo-parietal & Occipital & Total \\
\hline $\begin{array}{l}\text { Minor } \\
\text { GCS }(13-15)\end{array}$ & 6 & 1 & 4 & 0 & 1 & 0 & 12 \\
\hline $\begin{array}{l}\text { Moderate } \\
\text { GCS }(8-12)\end{array}$ & 10 & 1 & 5 & 2 & 2 & 0 & 20 \\
\hline $\begin{array}{l}\text { Severe } \\
\text { GCS }(<8)\end{array}$ & 4 & 0 & 2 & 0 & 4 & 2 & 12 \\
\hline Total & 20 & 2 & 11 & 2 & 7 & 2 & 44 \\
\hline
\end{tabular}


Table 6: Types of operative management

\begin{tabular}{|l|c|}
\hline Operative management & $\begin{array}{c}\text { No of } \\
\text { cases }\end{array}$ \\
\hline Elevation & 10 \\
\hline Elevation with durorhaphy & 21 \\
\hline Elevation with epidural hemorrhage drainage & 10 \\
\hline Elevation with subdural hemorrhage drainage & 3 \\
\hline Total & 44 \\
\hline
\end{tabular}

Table 7: Complications seen in all patients of depressed skull fracture

\begin{tabular}{|l|c|c|}
\hline Complications & & Numbers \\
\hline $\begin{array}{l}\text { Intracranial } \\
\text { hematoma }\end{array}$ & Epidural Hematoma & 16 \\
\cline { 2 - 3 } & Subdural Hematoma & 4 \\
\cline { 2 - 3 } & $\begin{array}{c}\text { Intra-cerebral } \\
\text { hematoma }\end{array}$ & 1 \\
\hline \multicolumn{2}{|l|}{ Post-operative infection } & 3 \\
\hline Brain contusion & HC & 18 \\
\cline { 2 - 3 } & NHC & 2 \\
\hline Subarachnoid hemorrhage & 1 \\
\hline
\end{tabular}

Table 8: Associated injury along with depressed skull fracture

\begin{tabular}{|l|c|}
\hline Associated injuries & No of cases \\
\hline Blunt chest injury & 25 \\
\hline Blunt abdominal injury & 15 \\
\hline Injury to extremities & 30 \\
\hline Spinal injury & 7 \\
\hline Pelvis injury & 23 \\
\hline
\end{tabular}

Table 9: Hospital stay of all cases of the depressed skull fracture

\begin{tabular}{|l|c|}
\hline Hospital stay & No of patients \\
\hline $0-5$ days & 35 \\
\hline $6-10$ days & 17 \\
\hline $11-20$ days & 34 \\
\hline $21-30$ days & 10 \\
\hline
\end{tabular}

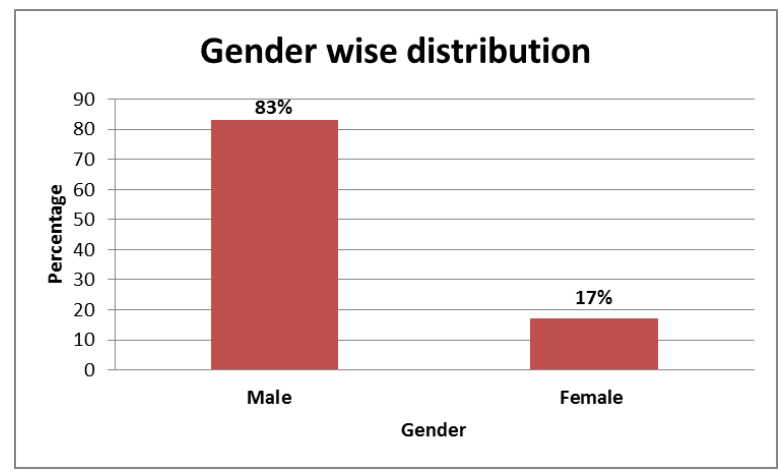

Fig. 1: Gender wise distribution of all participants

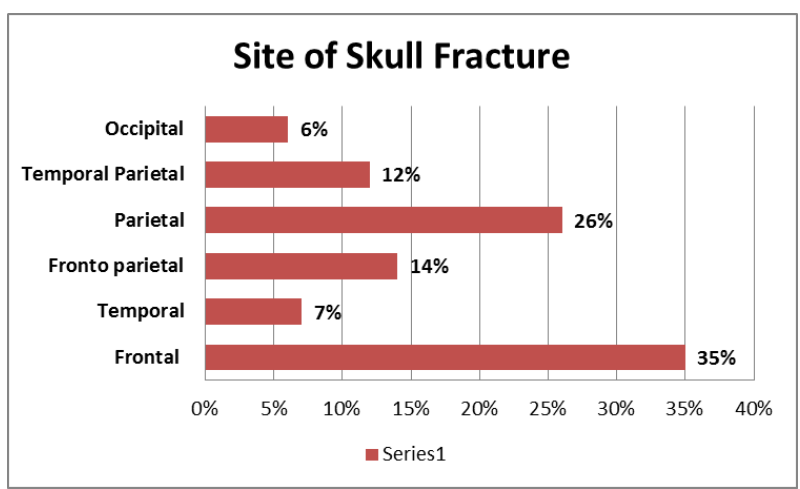

Fig. 2: Distribution of all participants according to site of fracture

\section{Discussion}

With rapid industrialization of cities urbanization and tremendous increase in high speed traffic flow trauma in general and depressed fracture of skull in particular are on increases, requiring augmented care, trained personnel and sophisticated equipment for saving the life of patients. In present study total 100 cases of depressed fracture of skull managed in a tertiary care hospital over two and half years were analyzed in context of causes and factors relating to treatment.

In present study commonest age was the early adults are commonly associated with the head injuries. While other study like Retnam RK et al shows that age lower than 10 years are more common than other. ${ }^{6}$ Also gender wise distribution of the both studies are nearly similar. This is because of males being more mobile universally and being more prone to accidents and also exposed to flights and assaults. In countries like India, females are more have life in house hold works and so, they are having less exposed to the factors which are prone to cause head injury. The higher ratio in males could be explained due to thicker and stronger skull in males which can absorb the impact force. Hence, males are more likely to get depressed fracture while females are more prone to linear fractures. ${ }^{7}$ While female have more linear fracture than the depressed skull fracture. As far as the age is concerned younger age is more often affected because they are more active life than the older people.

Once again it needs no over emphasis that various cases of trauma in society will depends up on economic status, civilization, industrialization, road traffic and peacefulness in between races in city. In present study $43 \%$ were injured as a result of assault, $15 \%$ were injured due to fall and $41 \%$ due to vehicular accidents and only $1 \%$ due to fall of object. Study by Retnam RK et al shows that fall of patients are most common mode of head injury $(50.6 \%)$, which is mainly because of age difference in the study. ${ }^{6}$ While 
another study by Prakash A shows that assault is commonest cause with $36.42 \% .^{8}$ In present study common age of injury is early adult life while in Retnam RK et al had common age of injury is $<10$ years. Other study by Ahmed $\mathrm{S}$ found the most common cause for depressed skull fracture as road traffic accident $(72 \%)$ followed by fall from the height $(12 \%)$ and fall of object on the head $(6 \%) .{ }^{9}$

The most common presenting symptoms was vomiting in with $55 \%$ of total participants, followed by unconsciousness 20\%, convulsion $20 \%$ and shock $5 \%$. While most common symptom in study by Satardey RS et al and Retnam RK et al was unconsciousness $76 \%$ and $40 \% .^{10}$ Frontal region was most injured site in $35 \%$ of cases, followed by parietal $26 \%$ cases. While study by Retnam RK et al and Satardey RS shows commonest site was parietal with $37.9 \%$ and $48 \%$ respectively followed by frontal i.e. $31.6 \%$ and $34 \%$ respectively in both the studies. As assault was the commonest cause in present study frontal was the commonest site while in other studies parietal was common site because fall of patients was common cause of the head injury. It also gives idea about the severity of injury.

Compound fractures are most common with $94 \%$ in present study, which is similar with other study by Retnam KR et al (95\%). 44 patients were operated among these 94 patients. Dural tear was seen in 21 patients and 23 had closed Dural layer. ${ }^{6}$ The maximum numbers of cases of compound depressed skull fracture were in frontal region (34\%), followed by parietal region. While in study by Retnam KR et al series compound depressed fracture was common in parietal region followed by frontal and temporal. In present study associated injury encounter were blunt chest injury (25\%), abdominal injury (15\%), injuries to limbs (31\%), spinal injury (7\%) and pelvic injury (23\%). While in Madurai series they were blunt chest injury in $35 \%$, abdominal injury in $35 \%$, injury to limbs in $5 \%$, spinal injury in $5 \%$ and pelvis injury in $20 \%$ cases.

Closed depressed fracture can be followed up with conservative approach or approached surgically depending on the extent of depression, compression effects, or for cosmetic purpose. The depressed fractures overlying venous sinuses are left undisturbed to avoid hemorrhage. Majority of the patients were treated conservatively. Closed depressed fracture can be followed up with conservative approach or approached surgically depending on the extent of depression, compression effects, or for cosmetic purpose. ${ }^{11}$ The depressed fractures overlying venous sinuses are left undisturbed to avoid hemorrhage. Among them 2-3 participants converted into operative management. Indications were early epilepsy and deterioration of GC scale. Conservative modalities include intravenous antibiotics, analgesics, anticonvulsants and mannitol or furosemide. ${ }^{12,13}$ The indication of operative management was depressed skull fracture $>10 \mathrm{~mm}$ with severe head injury, associated intracranial hematoma, with midline shift and sign of hemiplegia.

Also after operative management, $3 \%$ patients develops infection while in other studies like Ratnem KR et al and Satardey et al studies shows $9 \%$ and $14 \%$ of infection respectively. So, in present study infections are very less than other studies. ${ }^{6,10}$ Also study by Satardey et al shows higher chances of mortality in patients with post-operative infections.

\section{Conclusion}

Assault is common with male and frontal region is commonly involved. Conservative management is better in patients with CT scan suggestive of depressed skull fracture nor more than $10 \mathrm{~mm}$ and not intracranial hematoma. Patients with depressed skull fracture with more than 10 $\mathrm{mm}$ with severe head injury and associate hematoma are better managed operatively.

\section{Source of Funding}

None.

\section{Conflict of Interest}

None.

\section{References}

1. Ali M, Ali L, Roghani IS. Surgical management of depressed skull fracture. JPMI. 2003;17(1):116-23.

2. Bullock MR, Chesnut R, Ghajar J, Gordon D, Hartl R, Newell DW, et al. Surgical management of depressed cranial fractures. Neurosurg. 2006;58(3 Suppl):S56-60.

3. Jennett B, Snoek J, Bond MR, Brooks N. Disability after severe head injury: Observations on the use of the Glasgow Outcome Scale. J Neurol Neurosurg Psychiatry. 1981;44:285-93.

4. Cowan BF, Segall HD, Zee CS. Neuroradiological assessment of depressed skull fracture: Axial versus skull roentgenography. Western Neuroradiological Society Annual Meeting; October, 1980.

5. American college of surgeons committee on trauma, editor. Advanced trauma life support for doctors, student course manual. Chicago: American College of Surgeons; 1997.

6. Retnam KR, Jawahar G, Natarajan M. Midline depressed fractures of the skull. J Indian Med Assoc. 1986;84(9):271-2.

7. Yavuz MS, Asirdizer M, Cetin G, Günay Balci Y, Altinkok M. The correlation between skull fractures and intracranial lesions due to traffic accidents. Am J Forensic Med Pathol. 2003;24:339-45.

8. Prakash A, Harsh V, Gupta U, Kumar J, Kumar A. Depressed Fractures of Skull: An institutional series of 453 patients and 
brief review of Literature. Asian J Neurosurg. 2018;13(2):222-6.

9. Ahmad S, Afzal A, Rehman L, Javed F. Impact of depressed skull fracture surgery on outcome of head injury patients. Pak J Med Sci. 2018;34(1):130-4.

10. Satardey RS, Balasubramaniam S, Pandya JS, Mahey RC. Analysis of factors influencing outcome of depressed fracture of skull. Asian J Neurosurg. 2018;13:341-7.

11. Braakman R. Depressed skull fracture: Data, treatment, and follow-up in 225 consecutive cases. J Neurol Neurosurg Psychiatry. 1972;35:395-402.

12. van den Heever CM1, van der Merwe DJ. Management of depressed skull fractures. Selective conservative management of nonmissile injuries. J Neurosurg. 1989;71:186-90.
13. Heary RF, Hunt CD, Krieger AJ, Schulder M, Vaid C.

Nonsurgical treatment of compound depressed skull fractures. J Trauma. 1993;35:441-7.

How to cite this article: Vala H, Vaja MA. Depressed skull fracture: Prognosis of patients after conservative or surgical management. IP Indian J Anat Surg Head Neck Brain. 2020;6(1):8-13. 